\title{
Use of Epifluorescence Microscopy and Transmission Electron Microscopy to Investigate Spatial and Temporal Dynamics of Prokaryotes, Viruses, and Viral Infections of Prokaryotes in Mono Lake, California
}

\author{
J. R. Brum*, G. F. Steward*, S. C. Jiang**, and R. Jellison*** \\ * Department of Oceanography, University of Hawaii at Manoa, 1000 Pope Rd, Honolulu, HI 96822 \\ ** Department of Environmental Health, Science, and Policy, 1367 Social Ecology II, University of \\ California Irvine, Irvine, California 92696 \\ *** University of California Santa Barbara, Sierra Nevada Aquatic Research Laboratory, 1016 Mt. \\ Morrison Rd, Mammoth Lakes, California 93546
}

Mono Lake is a large, alkaline, moderately hypersaline lake containing planktonic prokaryotes and viruses at concentrations that are among the highest reported for natural aquatic environments [1]. We investigated the temporal, vertical, and horizontal variability in microbial concentrations and viral infections of prokaryotes over a 10-month period in Mono Lake to test how these parameters are affected by the pronounced seasonality and strong vertical gradients in chemical, physical, and biological parameters in this lake. Viruses and prokaryotes were enumerated using epifluorescence microscopy after staining of the sample with SYBR Green I [2] (Figure 1). To investigate viral infections, samples were positively stained with $0.5 \%$ uranyl acetate and observed using a transmission electron microscope (LEO 912) with $100 \mathrm{kV}$ accelerating voltage. This enabled us to see through prokaryotic cells and determine the portion of cells that contained mature viruses, referred to as the frequency of visibly infected cells (FVIC), from which we calculated the fraction of mortality due to viral lysis (FMVL) [3]. Micrographs were taken of each infected cell (Figure 2) and were analyzed to determine burst size, intracellular virus diameter, and volume of infected cells.

Concentrations of prokaryotes and viruses ranged from $0.10-1.2 \times 10^{8} \mathrm{ml}^{-1}$ and $0.14-1.9 \times 10^{9} \mathrm{ml}^{-1}$, respectively, with the highest concentrations occurring in the spring (Figure 3). FVIC ranged from $<0.1$ to $3.5 \%$ for the community (Figure 4), but reached as high as $12.5 \%$ for coccoid cells in one sample. Averaged over the water column, the estimated FMVL for prokaryotes ranged from a low of $3.73 \%$ in September to a high of $15.9 \%$ in July. Burst size, intracellular virus diameters, and volumes of infected cells were temporally variable with a trend of decreasing burst size through the spring and summer as a result of larger viruses infecting smaller cells. In contrast, these parameters did not differ systematically among stations or between the anoxic and oxic layers of the lake. The data suggest that seasonal forcing is the primary source of variability in viral infections in the lake. Overall, viral lysis appears to make modest contribution to the mortality of prokaryotes, but high virus-host contact rates suggest that viruses are likely to influence the clonal diversity of picoplankton in the lake.

[1] S. C. Jiang, et al., Microb. Ecol. 47 (2004) 9.

[2] R. T. Noble and J. A. Fuhrman, Aquat. Microb. Ecol. 14 (1998) 113.

[3] B. Binder, Aquat. Microb. Ecol. 18 (1999) 207.

[4] This work was supported by the National Science Foundation under grants DEB01-29174, DEB01-30528, and DEB01-29160. We thank Sandra Roll, Kimberly Rose, and Tina Carvalho. 


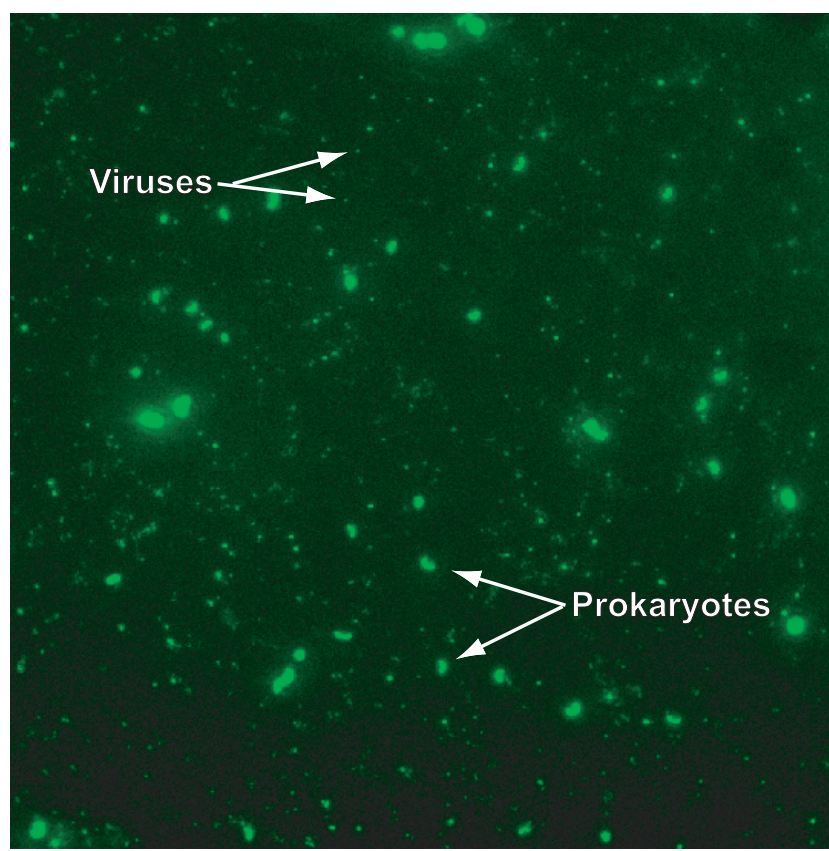

Fig. 1. Epifluorescence micrograph of a sample from $2 \mathrm{~m}$ in Mono Lake which has been stained with the fluorescent DNA stain SYBR Green I. Examples of prokaryotes and viruses are indicated with arrows.
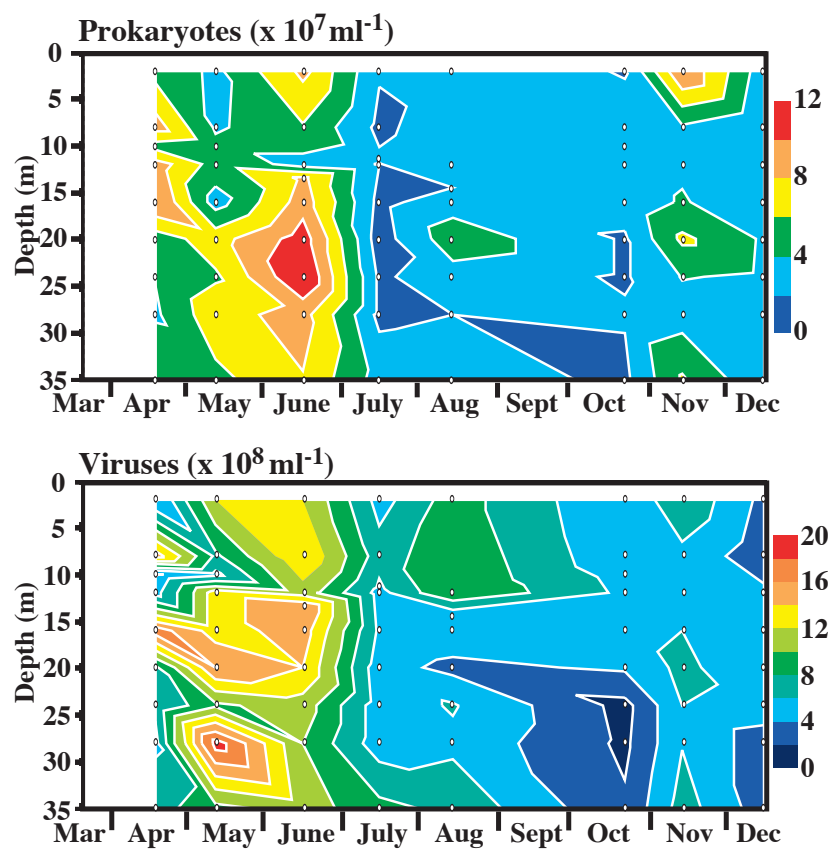

Fig. 3. Time series contours of prokaryotes and viruses in depth profiles at Station 6 in Mono Lake. Circles correspond to depths and dates of sample collection.

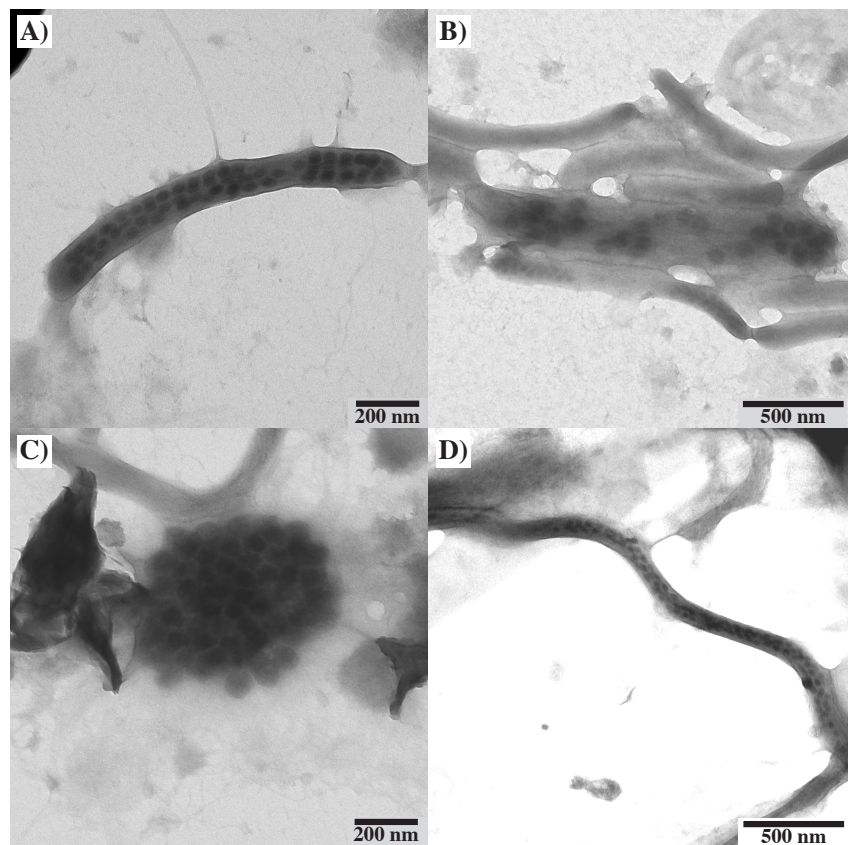

Fig. 2. Transmission electron micrographs of visibly infected cells representing the four cell morphotypes observed throughout the study. Micrographs show examples of an infected thin rod (A), an infected fat rod in the center of the micrograph (B), an infected coccoid cell (C), and a segment of an infected spirilla cell (D).

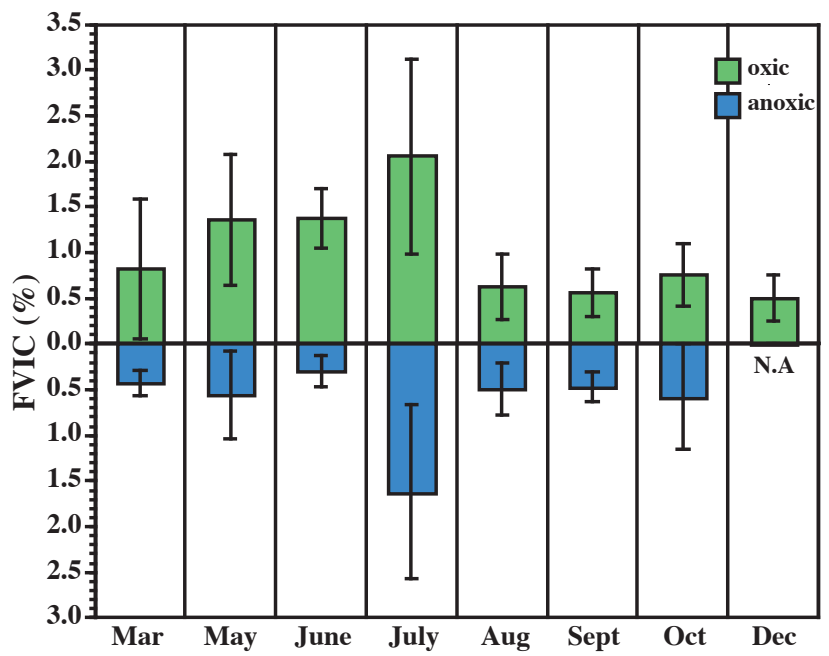

Fig. 4. Average FVIC of samples collected from the oxic and anoxic zones at Station 6. The plot of FVIC in the anoxic zone is inverted in order to show the overall temporal trend of FVIC from the oxic and anoxic zones together. Error bars represent one standard deviation of the mean. The entire water column was oxygenated in December. 